\title{
INTRODUCTION OF HUMAN PAPILLOMAVIRUS (HPV) VACCINATION IN BELGIUM, 2007-2008
}

\author{
C Simoens ${ }^{1}$, M Sabbe $^{2}$, P Van Damme ${ }^{3}$, P Beutels ${ }^{4,5}$, M Arbyn (marc.arbyn@iph.fgov.be) $)^{1,6}$ \\ 1. Unit of Cancer Epidemiology, Scientific Institute of Public Health, Brussels, Belgium \\ 2. Unit of Infectious Diseases, Scientific Institute of Public Health, Brussels, Belgium \\ 3. Centre for the Evaluation of Vaccination, Vaccine and Infectious Disease Institute, University of Antwerp, Antwerp, Belgium \\ 4. Centre for Health Economics Research and Modelling Infectious Diseases (CHERMID), Vaccine and Infectious Disease Institute, \\ University of Antwerp, Antwerp, Belgium \\ 5. School of Public Health, University of Sydney, Sydney, Australia \\ 6. Belgian Cancer Centre, Scientific Institute of Public Health, Brussels, Belgium
}

This article was published on 19 November 2009.

Citation style for this article: Simoens C, Sabbe M, Van Damme P, Beutels P, Arbyn M. Introduction of human papillomavirus (HPV) vaccination in Belgium, 2007-2008. Euro Surveill. 2009;14(46):pii=19407. Available online: http://www.eurosurveillance.org/ViewArticle.aspx?ArticleId=19407

This paper documents the progress of human papillomavirus (HPV) vaccine introduction in Belgium. Information on vaccine use is based on sales statistics and reimbursement claims. From November 2007 to November 2008, the National Institute for Health and Disability Insurance reimbursed the HPV vaccine for girls aged between 12-15 years. In December 2008, the age limit was extended to include girls up to the age of 18. In November 2008 , the total number of HPV vaccines sold exceeded 530,000 doses. The number of vaccines reimbursed in Belgium, for the period November 2007-November 2008, corresponds to the amount required to fully vaccinate $44 \%$ of all girls aged between 12-15 years. However, the trend was decreasing over the last 10 months. By the current reimbursement policy, we can expect that maximum half of the target population can be reached. In Flanders (one of the three Communities in Belgium), the intention is to start, from September 2010, with a free school-based HPV immunisation for girls in the first year of secondary school (12 years of age), complemented with vaccination by a physician of choice. This strategy ensures a higher HPV vaccine coverage which is expected to be as high as the current coverage in the hepatitis $B$ vaccination programme (approximately $80 \%$ ) offered to boys and girls in the same age group and under the same circumstances.

\section{Introduction}

In 2004, 651 cases of cervical cancer (European-age standardised rate (E-ASR) 8.5/100,000 women-years) were reported in Belgium, and approximately 264 women (E-ASR $3.8 / 100,000$ women-years) died from the disease $[1,2]$. Currently, screening for cervical cancer is mainly opportunistic in Belgium $[3,4]$. The screening coverage for cervical cancer, in the target age group (25-64 years), with a three-year interval, was 59\% in 2000. However, the modal screening interval is 12 months, whereas the recommended interval is 36 months. Moreover, screening is often offered to women younger than 25 years of age. Therefore, the number of smears taken annually could theoretically cover the whole target population [5]. Nevertheless, organised screening according to European guidelines and in collaboration with the three Communities (Flemish, French, and Germanophonic), is planned within the new Cancer Plan [6,7]. It is estimated that $72 \%$ of all cervical cancers in Europe and North America are caused by the oncogenic human papillomavirus (HPV) types 16 and 18 [8]. The current paper updates a previous report on HPV vaccine introduction in Belgium, Luxembourg and the Netherlands [9], and provides more detailed information on the Belgian situation.

\section{Recommendations and decision making in Belgium}

On 2 May 2007, the Belgian Superior Health Council (SHC) made its first recommendations regarding vaccination against infections caused by HPV. The only vaccine available at that moment was the quadrivalent HPV-vaccine, containing virus-like particles of HPV types 6, 11, 16 and 18 (Gardasil, licensed in Belgium on 20 September 2006). Summarising the recommendations of the SHC to the health authorities:

- Organised HPV vaccination should be offered to a one-year birth cohort of girls between 10 and 13 years of age [10].

- Girls should preferably be vaccinated through the school health system within a scholar calendar year, free of charge, as currently done for hepatitis B vaccination [11]. In Belgium, 70-80\% of the vaccines for school-age children are given through the school health system. Practicing physicians (general practitioners (GPs), paediatricians and gynaecologists) have a complementary role in this. The SHC therefore recommended that for HPV too, parents should have the option of having their child vaccinated by such practicing physicians.

- The additional protective effect of organised catch-up vaccination up to the age of 15 years was recognised but only recommended if health-economic evaluation would confirm that it is cost-effective.

- Vaccination at older ages (14-26 years) can be considered when delivering personal healthcare, for instance during a consultation related to contraception, taking into account prior sexual experience and stressing the importance of safe sex. Systematic preliminary HPV testing before vaccination was not recommended.

- It is considered necessary to set up an organised screening programme according to European guidelines [7,9], to register administration of the HPV vaccine and to monitor their effects. 
The recommendation was updated on 5 December 2007 to include the bivalent vaccine (HPV types 16 and 18) (Cervarix, licensed in Belgium on 24 September 2007).

The SHC is the link between government policy and the scientific world in the field of public health. The council provides independent advice and recommendations to the Minister, on his/her specific request for information or on its own initiative. The Communities are free to implement these recommendations, even independent of each other.

The National Institute for Health and Disability Insurance (NIHDI) is a federal institution that organises, manages and supervises the correct application of the 'compulsory insurance' in Belgium [12]. It covers the whole population officially residing in Belgium. The NIHDI has decided, independently of the recommendation of the $\mathrm{SHC}$, to reimburse opportunistic HPV vaccination for girls between the age of 12 and 15 years (for the quadrivalent vaccine since 1 November 2007 [13] and for the bivalent vaccine since 1 May 2008 [14]). In the framework of the National Cancer Plan, the age range for reimbursement was extended to include the age of
18 years as of 1 December 2008 [6]. This reimbursement of the HPV vaccines was communicated widely both in the scientific and the popular press.

The organisation of preventive healthcare in Belgium, including the management of the routine vaccination programme, is a responsibility of the three Communities. However, since 2004, in recognition of the high prices of some new vaccines, the NIHDI has been co-funding two thirds of the costs for vaccine purchase (only for vaccines purchased via tender, such as for the hepatitis $B$ adolescent vaccination programme, the infant hexavalent vaccination programme, etc.). This mechanism of shared funding requires consensus on vaccination policies between all three Communities and federal authorities (the federal Ministry of Health together with the NIHDI). In 2008, the Ministry of the Flemish Community responsible for public health endorsed the recommendations of the SHC and the Flemish Vaccination Platform regarding HPV vaccination: i.e. offering HPV vaccination to a oneyear birth cohort of girls between 10-13 years of age [15]. However, the Ministry of Health of the French Community did not follow the SHC advice [15]. Girls aged 12-18 years from the French

F I G U R E

Number of vaccines sold and number of vaccines reimbursed per month for girls between 12 and 15 years of age, Belgium, Nov 2006-Nov 2008

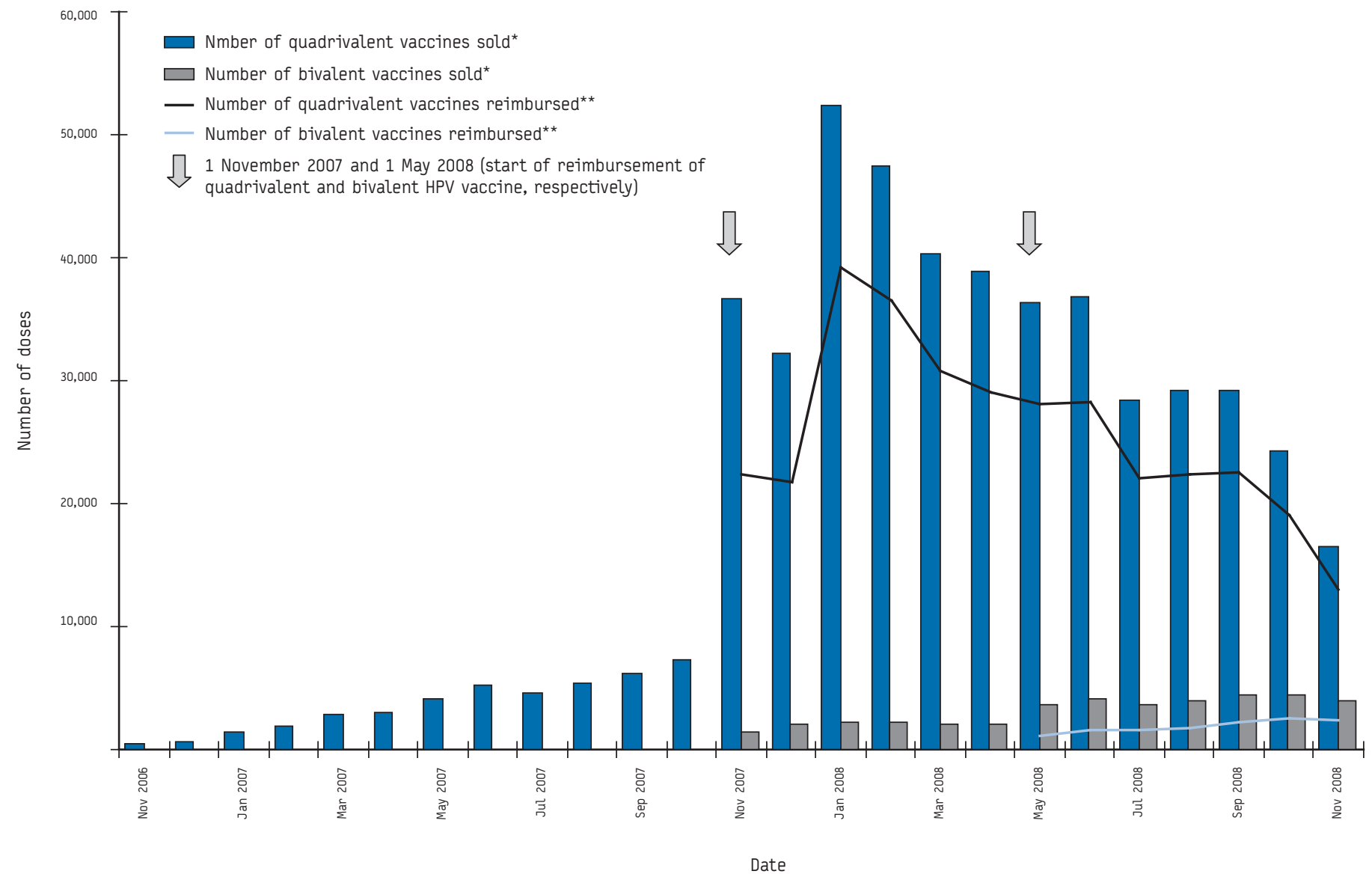

* Source: Intercontinental Marketing Services (IMS) Health

** Source: The Belgian National Institute for Health and Disability Insurance

HPV: human papillomavirus 
Community will be offered HPV vaccination by their GP or another physician, with the cost of the HPV vaccine partially reimbursed by the NIHDI and the remaining cost carried by the patient. Until now, the Germanophonic Community has not made a decision regarding a generalised immunisation programme for school girls against HPV.

Recently, legislation has changed and the consensus on vaccination policies between communities is no longer required, allowing for asymmetric immunisation policies over the different Communities [16]. The intention is to start free school-based HPV vaccination, at least in Flanders, in the school year 2010-2011, in a one-year cohort of girls in the first year of secondary school (12 years of age).

\section{Vaccine sales and reimbursement data}

Information on the total number of HPV vaccines sold in Belgium (complete wholesale data, not accounting for administration of the vaccine), was obtained from Intercontinental Marketing Services (IMS) Health (Figure: bars). IMS statistics show a cumulative amount of approximately 43,000 doses of the quadrivalent vaccine sold up to October 2007 (after the start in November 2006, sales figures gradually increased from ca. 400 to ca. 7,200 monthly doses). After the start of reimbursement in November 2007, a rapid increase in the monthly number of HPV vaccine doses sold was seen, up to 52,000 in January 2008. From then on, sales decreased progressively to 20,000 doses in November 2008. In total, about 532,000 HPV vaccine doses were sold in Belgium, up to November 2008.

The NIHDI HPV vaccine reimbursement data are also shown in the Figure (line curve), for the period November 2007-November 2008 (source NIHDI). At the start of reimbursement (in November and December 2007), the monthly number of reimbursed doses of the quadrivalent vaccine was around 22,000. In January 2008, the number increased to ca. 39,000 doses, but decreased afterwards to ca. 15,000 doses in November 2008. Over 1,000 doses of the bivalent vaccine were reimbursed in May 2008, which was the first month of reimbursement for this type of vaccine. This number increased up to 2,350 per month in November 2008. In total, over the 13-month period, 348,000 HPV vaccine doses were reimbursed. These reimbursed vaccines were administered by the GPs, paediatricians or gynaecologists of the 12-15 year-old girls.

The proportion of total vaccines sold that were reimbursed over the period where both IMS and reimbursement data were available, increased from 59\% in November 2007 to about 75\% in November 2008. The proportion of sold vaccines that were bivalent increased progressively from less than $4 \%$ before reimbursement to $19 \%$ in November 2008. The difference between sales and reimbursement figures (see Figure) presumably corresponds to vaccination beyond the target population, probably women older than 15 years buying it privately.

In Belgium, ca. 348,000 doses of HPV vaccine (both quadrivalent and bivalent) were reimbursed over a period of 13 months, which corresponds to an annual average of about 320,000 (ca. 27,000 per month); with this amount of vaccines one could theoretically reach a full three-dose coverage of $44 \%$ of all girls aged $12-15$ years residing in Belgium. Around 61,000 monthly doses would be needed to reach complete coverage. Over the last six documented months ca. 31,500 doses were reimbursed per month and this quantity was following a negative trend. If this trend continues, we can expect that maximum half of the target population could be reached by the current reimbursement policy in Belgium.

\section{Discussion and conclusion}

The current policy of administration of the HPV vaccine in Belgium is estimated to cover maximum half of the targeted population. School-based free vaccination, complemented with vaccination by a physician of choice, is expected to guarantee a higher level of HPV vaccine coverage, effectiveness, cost-effectiveness and equity in healthcare access. Data from the recent immunisation coverage study in Flanders (2008) show that hepatitis B vaccine coverage offered at the age of 12 years achieved a coverage of approximately 90\% [17]. In Flanders (one of the three Communities in Belgium), the intention is to start, from September 2010, a free school-based HPV immunisation, which is the preferred strategy option for HPV vaccine delivery in European countries proposed by the European Centre for Disease Prevention and Control [18]. In Flanders, this will be complemented by vaccination by a physician of choice (as is the situation for the national adolescent hepatitis $B$ vaccination programme).

Current HPV vaccines are expensive, the duration of elicited immunity is still unknown and not all oncogenic HPV types are included. Therefore, careful surveillance is needed. In Belgium, the National Cancer Plan foresees registration of all organised vaccination efforts. Moreover, linkage of HPV vaccination status with the Belgian Cancer Registry is foreseen. However, international consultation is desirable, in order to orient the design of local surveillance plans allowing for international comparison.

Data on HPV vaccine sales and reimbursement will be collected continuously from the IMS and the NIHDI, both sources described in this paper. In the near future, the Scientific Institute of Public Health in collaboration with the Intermutualistic Agency, will analyse individual patient data from all reimbursed HPV vaccinations which will allow to estimate HPV vaccination coverage by number of doses, age and geographic unit.

\section{Acknowledgements}

Financial support was received from (1) IWT (Institute for the Promotion of Innovation by Science and Technology in Flanders, project number 060081), Brussels, Belgium; (2) the Belgian Cancer Foundation (Belgische Stichting tegen Kanker), Brussels, Belgium; and (3) the National Cancer Plan, Brussels, Belgium.

Competing interest

C Simoens and M Arbyn received travel funding from GSK and SPMSD, respectively (before 2008). P Van Damme has been principal investigator of bivalent and quadrivalent HPV vaccine trials, for which the University of Antwerp obtains contractual funding. All other authors declare no conflict of interest.

\section{References}

1. Arbyn M, Raifu AO, Autier P, Ferlay J. Burden of cervical cancer in Europe: estimates for 2004. Ann Oncol. 2007;18(10):1708-15.

2. Arbyn M, Raifu AO, Bray F, Weiderpass E, Anttila A. Trends of cervical cancer mortality in the member states of the European Union. Eur J Cancer 2009;45(15):2640-8.

3. Arbyn M, Van Oyen H. Cervical cancer screening in Belgium. Eur J Cancen 2000;36(17):2191-7.

4. Arbyn M, Rebolj M, de Kok IM, Becker N, O’Reilly M, Andrae B. The challenges for organising cervical screening programmes in the 15 old member states of the European Union. Eur J Cancer. 2009;45(15):2671-8. 
5. Arbyn M, Simoens C, Van Oyen H, Foidart JM, Goffin F, Simon P, et al. Analysis of 13 million individual patient records pertaining to Pap smears, colposcopies, biopsies and surgery on the uterine cervix (Belgium, 1996-2000). Prev Med. 2009;48:438-43.

6. Onkelinx L. [National Cancer Plan]. Ministry of Public Health and Social Affairs.10 March 2008. Dutch. Available from: http://www.laurette-onkelinx. be/articles_docs/32_initiatieven_N.pdf

7. European Commission. European Guidelines for Quality Assurance in Cervical Cancer Screening. 2nd ed. Luxembourg: Office for Official Publications of the European Communities; 2008.

8. Muñoz N, Bosch FX, Castellsagué X, Diaz M, de Sanjose S, Hammouda D, et al. Against which human papillomavirus types shall we vaccinate and screen? The international perspective. Int J Cancer. 2004;111(2):278-85.

9. Arbyn M, Simoens C, Van Damme P, Scharpantgen A, Meijer CJLM, Beutels P. Introduction of HPV vaccination in Belgium, Luxembourg and the Netherlands. Gynecol Obstet Invest. In press 2009.

10. Hoge Gezondheidsraad/Conseil Supérieur de la Santé. Vaccinatie tegen infecties veroorzaakt door het humaan papillomavirus/Vaccination contre les infections causées par le papillomavirus humain. [Vaccination against infections caused by human papillomavirus]. CSS. 2007. Dutch/French. Available from: http:// www.zorg-en-gezondheid.be/uploadedFiles/NLsite/Preventie/Infectieziekten en_vaccinaties/Vaccinaties/professionelen/ adviezen_Hoge_Gezondheidsraad/ HGR_8367_NL\%2OHPV.pdf and https://portal.health.fgov.be/pls/portal/docs/PAGE/ INTERNET PG/HOMEPAGE MENU/ABOUTUS1 MENU/ INSTITUTIONSAPPARENTEES1 MENU/HOGEGEZONDHEIDSRAAD1_MENU/ADVIEZENENAANBEVELINGEN1_MENU/ ADVIEZENENAANBEVELINGEN1_DOCS/CSS_8367_FR.PDF

11. FitzSimons D, Vorsters A, Hoppenbrouwers K, Van Damme P, Viral Hepatitis Prevention Board (VHPB); European Union for School and University Health and Medicine (EUSUHM). Prevention and control of viral hepatitis through adolescent health programmes in Europe. Vaccine. 2007;25(52):8651-9.

12. Schokkaert E, Van de Voorde C. Health care reform in Belgium. Health Economics. 2005;14:S25-S39.

13. Donfut D. Belgisch Staatsblad/Moniteur belge. [Belgian Official Journal]. 19 October 2007. Ed3:54499-54500. Dutch/French.

14. Onkelinx L. Belgisch Staatsblad/Moniteur belge. [Belgian Official Journal]. 18 April 2008. Ed3:21186-21187. Dutch/French.

15. Minister Steven Vanackere. Commissievergadering: commissie voor welzijn, volksgezondheid en gezin. [Assembly of the Commission: commission of well being, public health and family]. Flemish Parliament. C11 WEL2. 1-7. 70ctober 2008. Dutch.

16. Heeren V. Belangrijke doorbraak inzake de preventie van baarmoederhalskanker [ Important breakthrough regarding the prevention of cervical cancer]. 4 March 2009. Dutch. Available from: http://www.veerleheeren.be/upload/ pb/090304_PB_VaccinBaarmoederhalskanker.pdf

17. Hoppenbrouwers K, Vandermeulen C, Roelants M, Boonen M, Van Damme P, Theeten $\mathrm{H}$, et al. Verslag over de immunisatie in Vlaanderen 2008. [Report on the immunisation coverage in Flanders 2008]. 14 April 2009. Dutch.

18. European Centre for Disease Prevention and Control (ECDC). Guidance for the introduction of HPV Vaccines in EU Countries. Stockholm: ECDC; 2008 Available from: http://ecdc.europa.eu/en/publications/Publications/0801_GUI_ Introduction_of_HPV_Vaccines_in_EU.pdf 